FEDERAL RESERVE BANK OF MINNEAPOLIS

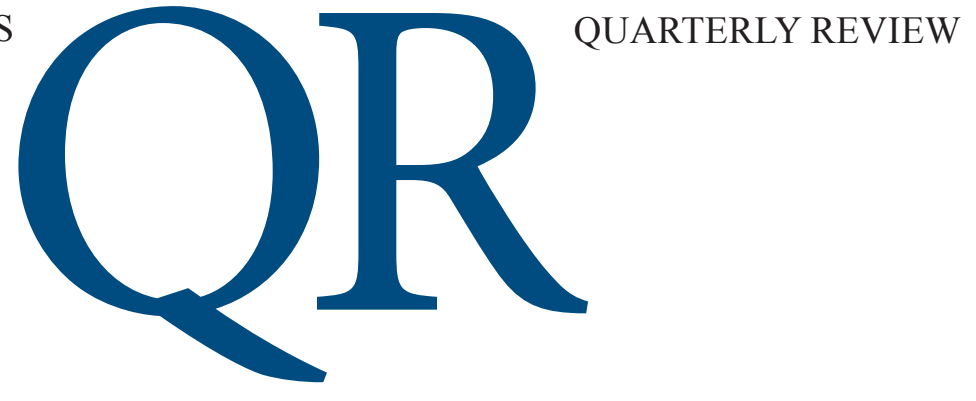

Trading Off Consumption and COVID-19 Deaths

Robert E. Hall

Charles I. Jones

Peter J. Klenow 


\section{FEDERAL RESERVE BANK OF MINNEAPOLIS \\ Quarterly Review Vol. 42, No.1}

ISSN 0271-5287

https://doi.org/10.21034/qr.4211

This publication primarily presents economic research aimed at improving policymaking by the Federal Reserve System and other governmental authorities.

The views expressed herein are those of the authors and not necessarily those of the Federal Reserve Bank of Minneapolis or the Federal Reserve System.

SENIOR VICE PRESIDENT AND DIRECTOR OF RESEARCH: Mark L. J. Wright

EDITOR: Juan Pablo Nicolini

ARTICLE EDITOR: James Holt

TECHNICAL SUPPORT: Shawn Hewitt

The Quarterly Review is published by the Research Division of the Federal Reserve Bank of Minneapolis. This has become an occasional publication; however, it continues to be known as the Quarterly Review for citation purposes. Subscriptions are available free of charge. To subscribe to the journal and be automatically notified whenever a new issue is published, please sign up at https://www.minneapolisfed.org/economic-research/

Quarterly Review articles that are reprints or revisions of papers published elsewhere may not be reprinted without the written permission of the original publisher. All other Quarterly Review articles may be reprinted without charge. If you reprint an article, please fully credit the source - the Minneapolis Federal Reserve Bank as well as the Quarterly Review - and include with the reprint a version of the standard Federal Reserve disclaimer (italicized above). Also, please send one copy of any publication that includes a reprint to the Research Division of the Federal Reserve Bank of Minneapolis. 


\title{
Trading Off Consumption and COVID-19 Deaths*
}

\author{
Robert E. Hall \\ Stanford University and NBER \\ Peter J. Klenow \\ Stanford University and NBER
}

Charles I. Jones

Stanford University and NBER

\begin{abstract}
This note develops a framework for thinking about the following question: What is the maximum amount of consumption that a utilitarian welfare function would be willing to trade off to avoid the deaths associated with COVID-19? The answer depends crucially on the mortality rate associated with the coronavirus. If the mortality rate averages $0.81 \%$, as projected in one prominent study, our answer is $41 \%$ of one year's consumption. If the mortality rate instead averages $0.44 \%$ across age groups, as suggested by a recent seroprevalence study, our answer is $28 \%$.
\end{abstract}

\section{Introduction}

Economies throughout the world are faced with a terrible question: How should we trade off large declines in consumption and GDP versus deaths from the coronavirus pandemic? As is well appreciated in economics, individuals make life-and-death decisions every day when deciding what job to take or whether to drive across town. We apply the basic framework used to evaluate these kinds of individual decisions to a utilitarian social welfare function to help us think about trading off consumption of survivors versus deaths from the pandemic. ${ }^{1}$

To see our basic result, suppose that, absent any actions, the pandemic would lead to an increased mortality at the rate $\delta$ among the population and that people have an average remaining life expectancy of $L E$ years. Let $v$ denote the value of a year of life measured in years of per capita consumption. The basic result of our calculation is that to avoid this risk, society would be willing to give up a fraction of one year's consumption given by

$$
\alpha \approx \delta \cdot v \cdot L E .
$$

The right hand side of (1) is the value of the lost life years relative to annual consumption. The intuition for this result is straightforward. The "value of a year of life" $v$ is the price

${ }^{*}$ We are grateful to Romans Pancs and Katelyn Ann Tynan for helpful comments. Contact: REHall@Stanford.edu, Chad.Jones@Stanford.edu, and Klenow@Stanford.edu. 
of life in units of annual consumption: each year of life lost is equivalent to $v$ years of consumption. The fraction of consumption society is willing to sacrifice is simply this price multiplied by the expected quantity (per capita) of life years lost because of the pandemic.

To illustrate quantitatively, suppose that $\delta=0.81 \%$ (consistent with the early estimates from the Imperial College London study); suppose $v=6$ so that a year of life is worth six times annual consumption (based on EPA value of life numbers); and suppose $L E$ for victims is 14.5 years (again based on the Imperial College London study). According to the formula, this would make society willing to give up $70.5 \%$ of consumption for a full year to avoid the elevated mortality associated with the pandemic.

We think this figure is too high for two reasons. First, since the Imperial College London study, some estimates of the mortality rate from the pandemic have been lower. A defensible lower estimate might be $0.44 \%$ for $\delta$, based on a seroprevalence study in Indiana. ${ }^{2}$ For the same $v$ and $L E$, our estimate of the equivalent consumption loss is $38 \%$ with this lower mortality rate, rather than $70.5 \%$.

Second, the approximation in (1) involves linearizing the utility function. Taking into account curvature will naturally make society less willing to cut consumption. The more consumption is reduced, the higher the marginal pain of reducing it further. With the original $v, L E$, and $\delta$, taking into account diminishing marginal utility lowers the equivalent consumption loss from $70.5 \%$ to $41.3 \%$. If we also take into account a lower death rate, we arrive at a willingness to curtail consumption by $28 \%$ (down from $38 \%$ ) for one year to avoid coronavirus-related deaths.

\section{Model}

Suppose lifetime utility for a person of age $a$ is

$$
V_{a}=\sum_{t=0}^{\infty} \beta^{t} \bar{S}_{a, t} u\left(c_{t}\right)=u\left(c_{0}\right)+\beta S_{a+1} V_{a+1},
$$

where $S_{a+1}$ is the probability a person age $a$ survives to $a+1$ and $\bar{S}_{a, t}=S_{a+1} \cdot S_{a+2} \cdot \ldots \cdot S_{a+t}$ is the probability a person age $a$ survives for the next $t$ years; $0<\beta<1$ is the pure time discount factor; and $u(c)$ is flow (current year) utility from consumption $c$.

Suppose the population initially contains $N_{a}$ people of age $a$ and a total population $N=\sum_{a} N_{a}$. And suppose that the pandemic means that the survival rate for each group falls from $S_{a+1}$ to $S_{a+1}-\delta_{a+1}$ for one year. Our question is: What fraction $\alpha$ of consumption in the initial year is everyone willing to give up to avoid this risk?

Let $\lambda \equiv 1-\alpha$, and to simplify, let's assume that consumption is the same for all individuals. Motivated by (2), consider the following variations on lifetime utility:

$$
V_{a}(\lambda, \delta)=u(\lambda c)+\beta\left(S_{a+1}-\delta_{a+1}\right) V_{a+1}(1,0),
$$

where $V_{a}(\lambda, \delta)$ is the lifetime utility of a person age $a$ whose consumption is reduced by factor $\lambda$ in the current year and whose mortality rate increases by $\delta_{a+1}$ for the year. After the year is over, their consumption and mortality revert back $(\lambda=1, \delta=0)$.

Let $W(\lambda, \delta)$ denote utilitarian social welfare across all ages and $\delta$ denote the vector of 
death rates from the pandemic:

$$
W(\lambda, \delta)=\sum_{a} N_{a} V_{a}(\lambda, \delta)=N u(\lambda c)+\beta \sum_{a}\left(S_{a+1}-\delta_{a+1}\right) N_{a} V_{a+1}(1,0) .
$$

The equivalent variation we have in mind satisfies $W(\lambda, 0)=W(1, \delta)$ :

$$
\begin{aligned}
N u(\lambda c)+\beta \sum_{a} S_{a+1} N_{a} V_{a+1}(1,0) & =N u(c)+\beta \sum_{a}\left(S_{a+1}-\delta_{a+1}\right) N_{a} V_{a+1}(1,0) \\
\Rightarrow u(c)-u(\lambda c) & =\beta \sum_{a} \delta_{a+1} \omega_{a} V_{a+1}(1,0)
\end{aligned}
$$

where $\omega_{a} \equiv N_{a} / N$ is the initial population share of group $a$.

Now, take a Taylor expansion around $\lambda=1$ to see that

$$
u(\lambda c) \approx u(c)+u^{\prime}(c) c(\lambda-1) .
$$

Plugging this into (3) gives

$$
\alpha \equiv 1-\lambda \approx \beta \sum_{a} \delta_{a+1} \omega_{a} \widetilde{V}_{a+1}
$$

where $\widetilde{V}_{a+1} \equiv V_{a+1}(1,0) /\left[u^{\prime}(c) c\right]$ is the value of life at age $a+1$ relative to the flow of consumption $c$. The division by the marginal utility of consumption, $u^{\prime}(c)$, converts utils into consumption units. Note that $\alpha \equiv 1-\lambda$, so that $\alpha$ is the fraction of consumption you give up (a number like 20\%).

Expression (4) has a nice intuition: the fraction of consumption that society is willing to give up is the sum of the expected number of deaths from the pandemic $\delta_{a} \omega_{a}$ at each age, weighted by the value of life at those ages as a share of consumption.

One more simplification is useful. When $\beta=1$ so there is no time discounting apart from mortality, equation (2) implies

$$
V_{a}(1,0)=u(c) \sum_{t=0}^{\infty} \bar{S}_{a, t}=u(c) \cdot L E_{a},
$$

where the last expression comes from the well-known result in demography that the sum of survival probabilities is the (cross-sectional) measure of life expectancy. That is, lifetime expected utility is the product of flow utility and life expectancy. Under this assumption,

$$
\widetilde{V}_{a+1}=\frac{u(c)}{u^{\prime}(c) c} \cdot L E_{a+1}
$$

Letting $v \equiv u(c) /\left[u^{\prime}(c) c\right]$ denote the value of a year of life relative to consumption (e.g., a 
number like six) and substituting into equation (4), we have, when $\beta=1$,

$$
\alpha \approx \sum_{a} \omega_{a} v \delta_{a+1} L E_{a+1}
$$

There are two examples of this formula that are helpful for intuition. First, suppose there is only a single representative agent in the economy. In this case, the equivalent variation describes how the consumer herself trades off her own mortality and her own consumption, and it gives the simple formula

$$
\alpha \approx \delta \cdot v \cdot L E
$$

This formula is the source of equation (1) in the Introduction.

Alternatively, suppose there are two groups: the old, who face mortality risk from the pandemic, and the young, who do not face any risk at all. Moreover, suppose the old are the fraction $1 / N$ of the population. In this case, a utilitarian planner would be willing to reduce everyone's consumption to avoid the extra mortality by

$$
\alpha \approx \frac{\delta \cdot v \cdot L E_{o}}{N}
$$

In all three cases, the intuition is the same. The "exchange rate" between consumption and a year of life is $v \equiv u(c) /\left[u^{\prime}(c) c\right]$. This is the price of life in the equation; it is multiplied by the quantity of life years lost in order to arrive at the equivalent variation by $\alpha \%$ in everyone's consumption.

\section{Calibration}

\section{A Representative Agent Calibration}

To get started, we first consider a calibration in which there is only a single agent in the economy, rather than two or more groups. In terms of the model just described, we set $N=1$ so that everyone is effectively in the "old" group, which faces the pandemic mortality risk, and everyone chooses to give up some fraction of one year's consumption to avoid that risk.

According to the Imperial College London study by Ferguson et al. (2020), the elevated death rate for all ages would be $0.81 \%$ without mitigation efforts. This figure is the product of their age-specific mortality rates (which aggregate to $1.1 \%$ for the entire age-weighted population) and the assumption that $75 \%$ of all age groups contract the virus in the absence of mitigation. Early estimates of the infection fatality rate (IFR) may end up being too high. As random testing of the type advocated by Stock (2020) continues to come in, some of the estimates are in line with the Imperial College London IFR of 1.1\%, and other estimates are lower. $^{3}$ 
Estimates of the value of a year of life used in the literature typically range from $\$ 100,000$ to $\$ 400,000 .{ }^{4}$ The U.S. Environmental Protection Agency (2020) recommends $\$ 7.4$ million for the value of remaining life in 2006 dollars for those between the ages of 25 and 55 . Given life expectancy at age 40 of just about 40 years in 2006, this implies a value of each year of remaining life equal to around $\$ 7.4 \mathrm{~m} / 40=\$ 185,000$. With consumption of $\$ 31,000$ per person in the U.S. in 2006, this implies that a year of life is worth six times annual consumption. We therefore take $v=6$ as our benchmark value. In terms of current consumption of $\$ 45,000$ per person of per year, this implies a VSLY (Value of a Statistical Life Year) of $\$ 270,000$ and a VSL of $\$ 10.8$ million.

Based on the Imperial College London death rates by age combined with the U.S. population distribution by age and life expectancy by age, we estimate victims' average life remaining to be 14.5 years. ${ }^{5}$ The age distribution of U.S. deaths from the pandemic so far has implied an average life expectancy of 14.1 years for victims. ${ }^{6}$ A recent study by Hanlon et al. (2020) emphasizes that those dying from coronavirus complications often suffer from comorbidities that would have lowered their life expectancy. They find relatively small effects, however: using the Hanlon et al. estimates reduces the remaining life years of victims to 13 years instead of 14.1 .

Taking the product of the parameters in the linearized equation (6) with the baseline death rate of $0.81 \%$ yields $\alpha=0.705$. With the lower death rate of $0.44 \%$, we get $\alpha=0.384$. Thus, a representative agent would be willing to sacrifice $70 \%$ of a year's consumption with the high death rate and $38 \%$ of consumption with the low death rate to avoid deaths from the pandemic. As we will see, assuming the marginal utility of consumption is constant in this Taylor approximation leads these numbers to overstate the exact calculation.

\section{Calibrating the Full Model}

Here, we use formula (5) with all age groups. More specifically, we use population shares by age from the U.S. Census source mentioned above, age-specific mortality rates in the Imperial College London study, and remaining years of life expectancy by age from the Social Security Administration data referenced above. Figure 1 displays the mortality rates, which rise sharply with age. Interestingly, they rise at a fairly stable $11 \%$ rate with age. Goldstein and Lee (2020), using data from several countries, report this same slope for how mortality changes with age. Figure 2 plots expected years of life remaining, which naturally fall with age. With these two ingredients, we incorporate that those at greatest risk of dying from the pandemic are those with the fewest years of life remaining. This means fewer life years are at stake than if the virus struck down all ages with the same probability, or if the virus were particularly lethal for younger people (as was the case with the Spanish flu).

Table 1 provides our estimates using all ages. The first panel is based on the simple formulas that linearize the utility function, equations (4) and (5) above. With $v=6$ and $\delta=0.81 \%$, we calculate $\alpha=0.705$, or $70 \%$. When using the lower $\delta=0.44 \%$, we obtain

$38 \%$. Because of the linearity of (4), these numbers turn out to be the same as the ones we calculated for the representative agent. The second panel in Table 1 shows exact results using CRRA utility with $\gamma=2$ rather than the linear approximation. When we incorporate diminishing marginal utility, society would be willing to sacrifice notably less: $41 \%$ of one year's consumption when $\delta=0.81 \%$ and $28 \%$ when $\delta=0.44 \%$. The table provides 
Figure 1

Pandemic Mortality by Age Group

MORTALITY RATE (IMPERIAL COLLEGE LONDON)

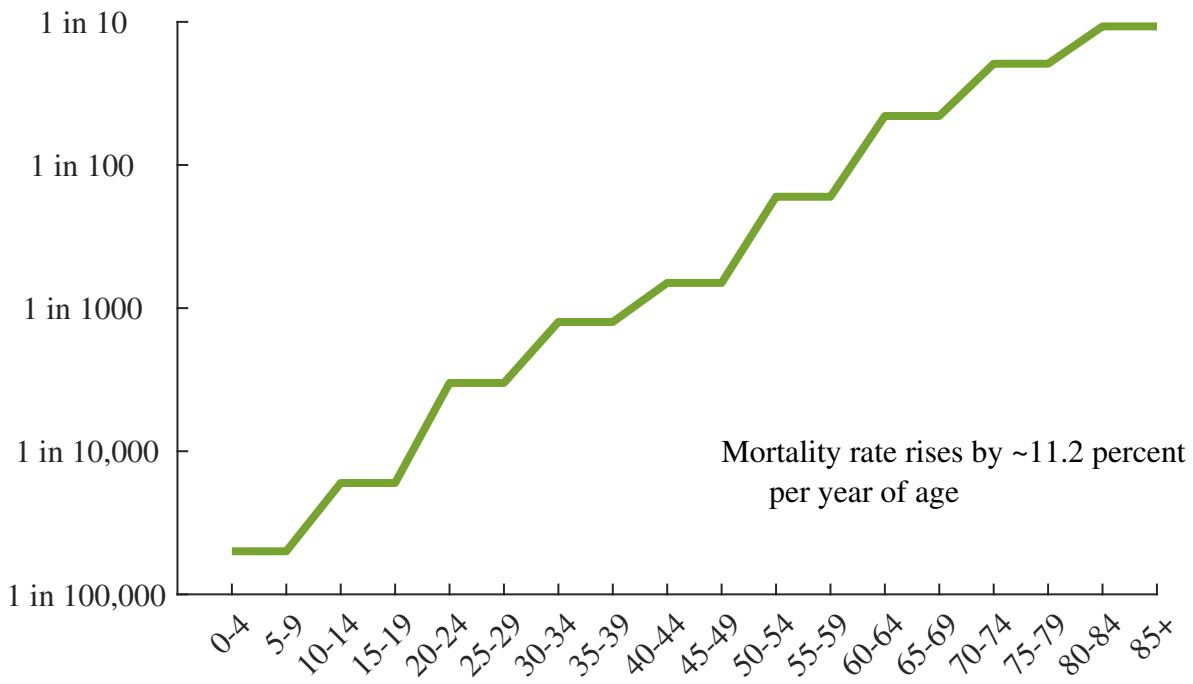

Note: Age-specific mortality rates associated with COVID-19 from Ferguson et al. (2020).

\section{Figure 2}

\section{Life Expectancy by Age Group}

LIFE EXPECTANCY (YEARS)

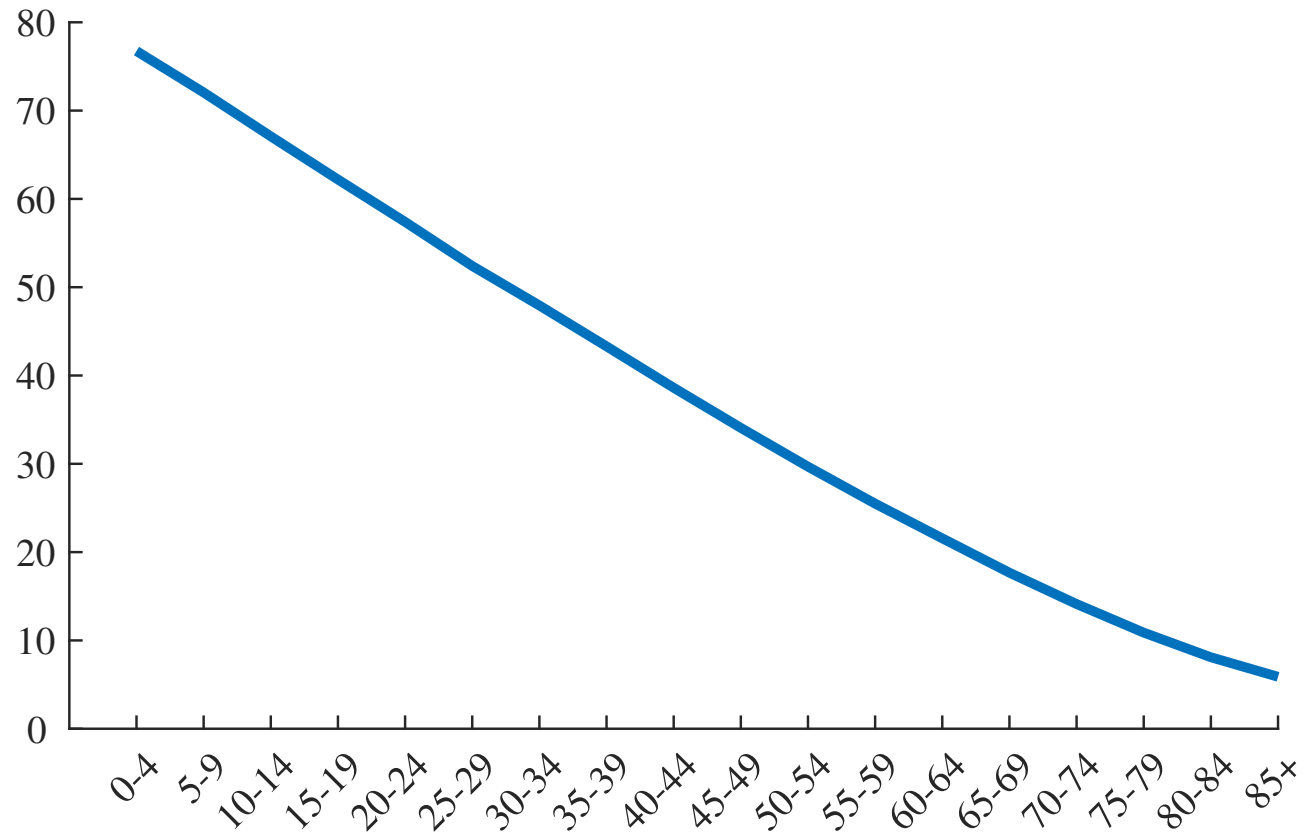

Note: Life expectancy by age group from the Social Security Administration: https://www.ssa.gov/oact/ STATS/table4c6.html. 
FEDERAL RESERVE BANK OF MINNEAPOLIS

QR

Table 1

Willing to Give Up What Percentage of Consumption?

\begin{tabular}{lccc}
$\begin{array}{c}\text { Average } \\
\text { mortality rate }\end{array}$ & \multicolumn{3}{c}{ Value of Life, $v-$} \\
$\delta$ & 5 & 6 & 7 \\
\hline \multicolumn{5}{c}{ Using } & Taylor series linearization: \\
$0.81 \%$ & 58.7 & 70.5 & 82.2 \\
$0.44 \%$ & 32.0 & 38.4 & 44.8 \\
\multicolumn{4}{c}{} \\
$0.81 \%$ & 37.0 & $\mathbf{4 1 . 3}$ & 45.1 \\
$0.44 \%$ & 24.2 & $\mathbf{2 7 . 7}$ & 30.9 \\
\hline
\end{tabular}

Note: The main entries in the table report the percentage of consumption a utilitarian planner would give up for one year in order to avoid the deaths from the pandemic in that year. The first panel reports the results using equation (5) with age-specific death rates using the Taylor approximation for $u(c)$. The second panel is exact but requires us to specify a utility function. We assume $u(c)=\bar{u}+c^{1-\gamma} /(1-\gamma)$. The formula, going back to equation (3), then becomes

$$
\lambda_{\text {full }}=[1+(\gamma-1) \alpha]^{\frac{1}{1-\gamma}},
$$

where $\alpha$ is the expression given in equation (5), and the full result is given by $\alpha_{\text {full }}=1-\lambda_{\text {full }}$.

estimates for higher and lower values of $v$ as well, as there is of course uncertainty about the value of a year of life. As one would expect, the higher the value of life, the bigger the sacrifice society should be willing to make to save life years.

Figure 3 breaks down the contribution of each group to $\alpha$ in the linearized case. It is not a priori obvious what this graph would look like. Mortality rates are low for younger people, but years of life remaining are high. The low mortality rate turns out to dominate at low ages, while the low remaining life expectancy dominates at high ages. The largest contributions come from the groups aged 60 to 74, where mortality and years of life remaining are both moderately high. With our more exact formula incorporating diminishing marginal utility, there is greater reason to sacrifice consumption to avoid mortality at young ages.

We can also express the loss of consumption (for individuals of all ages) equivalent to the mortality from the pandemic for individuals under 20, under 30, and so on. Table 2 reports our estimates using the exact formula with CRRA utility. Even though the median age of victims is around 75, saving the lives of victims below 75 makes up 34 points of the 41 percentage point total. And 23 points of the 41 percentage point total stem from saving the lives of victims under 65. This is relevant for assessing strategies (such as Sweden's) for isolating the elderly population most at risk from the coronavirus. Acemoglu et al. (2020) provide a normative analysis in this vein. 


\section{Figure 3}

\section{Contribution of Different Age Groups to $\alpha$} PERCENT CONTRIBUTION TO ALPHA (SUMS TO 100)

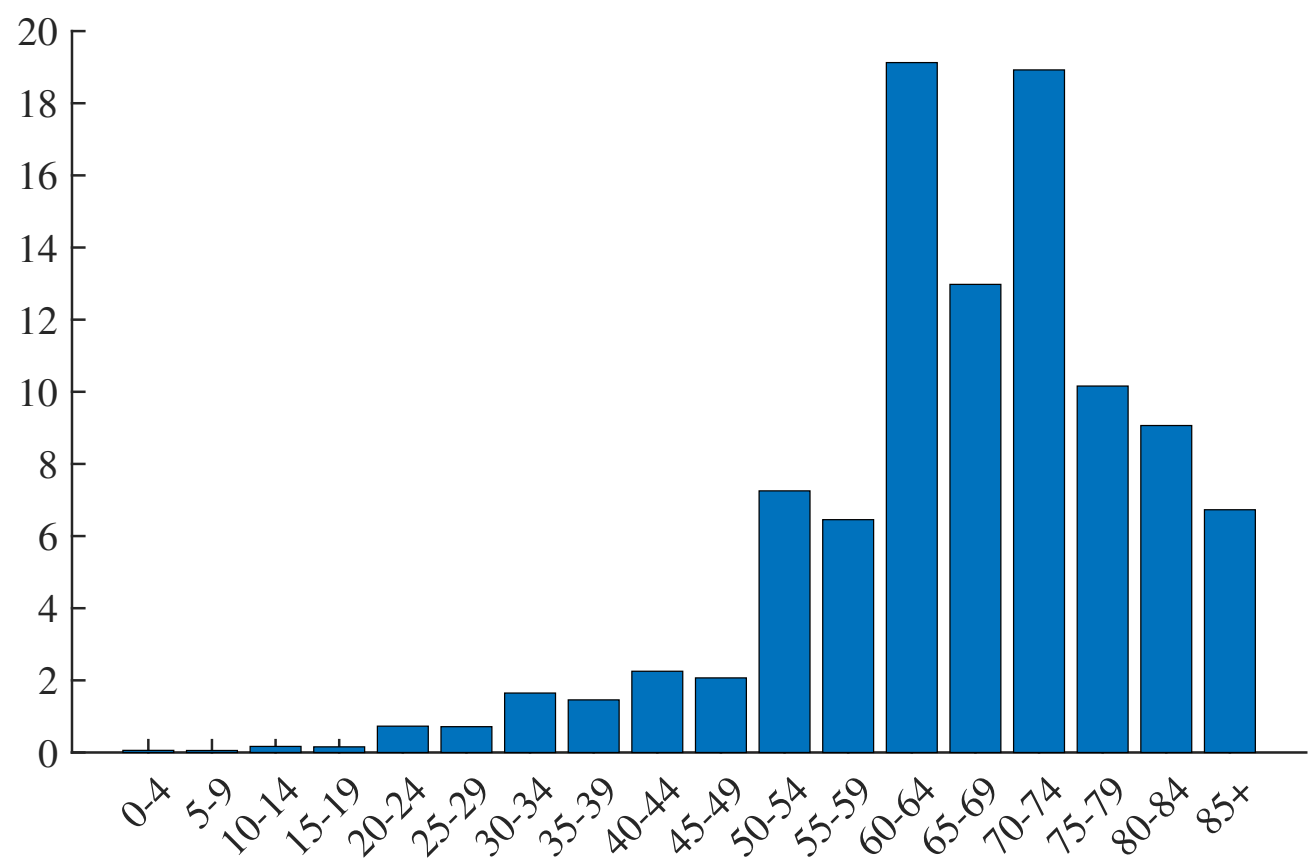

Note: Each bar is $\omega_{a} v \delta_{a+1} L E_{a+1}$, divided by the total $\alpha$ and multiplied by 100 . See equation (5).

Table 2

Percentage of Consumption to Avoid Deaths by Age

\begin{tabular}{cc} 
Age & $\%$ of consumption \\
\hline Under 20 & $0.3 \%$ \\
Under 30 & $1.3 \%$ \\
Under 40 & $3.4 \%$ \\
Under 50 & $6.2 \%$ \\
Under 60 & $14.0 \%$ \\
Under 65 & $\mathbf{2 2 . 9 \%}$ \\
Under 70 & $28.0 \%$ \\
Under 75 & $34.3 \%$ \\
Under All & $41.3 \%$
\end{tabular}

Note: Each entry is the percentage drop in consumption for all individuals that is equivalent to the deaths for the age group given. "Under 65," for example, is all deaths for those under age 65. The calculations are based on age-specific death rates consistent with an unconditional aggregate death rate of $\delta=0.81 \%$. The estimates use CRRA utility with $\gamma=2$. 


\section{Comparison with other estimates}

If we apply our estimate of $41 \%$ of consumption to $\$ 14.7$ trillion in consumption at an annual rate in the fourth quarter of 2019, we get $\$ 6.1$ trillion. Greenstone and Nigam (2020) arrive at $\$ 7.9$ trillion. They used a lower mortality rate than our $0.81 \%$, so deaths in their calculations were 1.7 million versus our 2.7 million. Based on age-specific values from Murphy and Topel (2006), they assume a VSLY of $\$ 315,000$ per life year lost versus our $\$ 270,000$. The biggest difference, however, is our use of diminishing marginal utility, which accounts for more than the entire difference in our estimates.

Zingales (2020) came up with a much larger estimate of $\$ 65$ trillion for the value of lost lives. He assumed many more deaths (7.2 million versus our 2.7 million) and many more years of life remaining for victims (50 years versus our 14.5 years). Like Greenstone and Nigam, his estimate does not incorporate diminishing marginal utility.

Thunström et al. (2020) use the entire EPA value of life for victims adjusted upward for inflation, or $\$ 10$ million. This is tantamount to assuming 40 years of remaining life per victim. They multiply this by an estimate of 1.24 million lives saved by social distancing to arrive at an aggregate value of \$12.4 trillion. We arrive at a much lower figure of $\$ 6.1$ trillion because of a lower number of years remaining per victim and diminishing marginal utility.

\section{Additional factors one could try to incorporate}

Our simple framework neglects many complicating factors. Below is a partial list.

GDP and consumption are of course distinct. One could imagine slashing consumption and leaving investment unchanged, as we have implicitly done. Then the drop in GDP and the one in consumption would be equal. But it might be optimal to cut investment and spread the loss of consumption over time. This would presumably lead to an intermediate number between our linearized and exact calculations.

Another issue is how consumption, earnings, and leisure vary by age. Victims from the pandemic are predominantly elderly. Their earnings are low, and their nonlabor income stems in part from capital income that would be bequeathed to survivors. On the other hand, their leisure is high. Murphy and Topel (2006) take these complications into account when they estimate the value of life years by age. Despite the fall in earnings at later ages, Murphy and Topel assign a high value to later life years. This would not change our estimates by a large amount.

A complete accounting would incorporate the impact of avoiding coronavirus-related deaths on mortality from other sources. It is not clear which way this would go on net. Social distancing may reduce deaths from traffic accidents and (eventually) air pollution. But it also may lead to delayed preventive care and worsened mental health.

For every person who dies from coronavirus complications, many more are hospitalized. The short-run and long-run impact on quality-adjusted life years for survivors is unclear. Even if, say, one-half of those infected are asymptomatic, for every person who dies from COVID-19 there would be 49 people with symptoms of varying severity. Thus the morbidity costs could conceivably be of the same order of magnitude as the mortality costs.

Social distancing might have other costs. The quality of leisure time may be adversely affected. Keeping children home from school may lower human capital investment if 
online instruction is not of similar quality. This may also increase in the inequality of such investments across children.

Early evidence suggests that lower earners have been hit harder by social distancing in the U.S. Cajner et al. (2020) examine this issue. Following Jones and Klenow (2016), one could quantify the loss in welfare from rising consumption inequality. In the CRRA case, if consumption is distributed lognormally across individuals with variance $\sigma^{2}$, then a one percentage point increase in the variance of consumption is equivalent to a $\gamma / 2$ percentage point reduction in consumption for everyone. When $\gamma=2$, each percentage point increase in the variance of log consumption would be equivalent to reducing aggregate consumption by $1 \%$. Thus, if mitigation efforts raise consumption inequality, this will cut into how much one would be willing to sacrifice average consumption to avoid coronavirus-related mortality.

Mortality from the pandemic has differed not only by age but also by education and race. See Gross et al. (2020) for evidence of a substantially higher mortality rate for blacks and Latinx relative to whites. Optimal mitigation efforts would take into account not only consumption inequality but also inequality of mortality and morbidity.

\section{Notes}

1. Classic references include Schelling (1968) and Usher (1973). Arthur (1981), Shepard and Zeckhauser (1984), and Murphy and Topel (2003) estimate the willingness to pay to reduce mortality risk and calculate the value of life. Nordhaus (2003) and Becker, Philipson, and Soares (2005) conclude that increases in longevity have been roughly as important to welfare as increases in non-health consumption, both for the United States and for the world as a whole. Hall and Jones (2007) use a related framework to study the rise in health spending as a share of GDP. Jones and Klenow (2016) construct consumption-equivalent welfare measures across countries and over time for combining consumption, life expectancy, leisure, and inequality. Adler et al. (2019) advocate a social welfare approach to these types of questions.

2. See more detail on the preliminary Indiana study here: https: / / news.iu.edu/stories / 2020 / 05 / iupui/releases/13-preliminary-findings-impact-covid-19-indianacoronavirus.html.

3. As mentioned above, the IFR in Indiana was estimated at $0.58 \%$. In New York City a seroprevalence study implied a IFR of $0.85 \%$, according to Wilson (2020). And in Spain, the IFR implied by a serology study was $1.1 \%$. See https: / / english.elpais.com/society/2020-05-14/ antibody-study-shows-just-5-of-spaniards-have-contracted-the-coronavirus.html.

4. Kniesner and Viscusi (2019) cite numbers used by the U.S. government ranging from $\$ 116 \mathrm{k}$ in 1998 to $\$ 369 \mathrm{k}$ in 2016. Cutler and McClellan (2001), in an older paper, used \$100k.

5. Our calculations are based on https: / / data.census.gov/cedsci/table?q=population\&tid= ACSDP1Y2018.DP05 and https: / / www.ssa.gov/oact/STATS/table4c6.html.

6. https://www.cdc.gov/nchs/nvss/vsrr/covid19/index.htm.

\section{References}

Acemoglu, Daron, Victor Chernozhukov, IvÃ $j n$ Werning, and Michael D Whinston. 2020. “Optimal Targeted Lockdowns in a Multi-Group SIR Model.” Working Paper, Working Paper Series 27102, National Bureau of Economic Research, May. doi:10 . 3386/w27102. http: / /www . nber. org/papers/w27102.

Adler, Matthew D., Maddalena Ferranna, James K. Hammitt, and Nicolas Treich. 2019. "Fair Innings: The Utilitarian and Prioritarian Value of Risk Reduction over a Whole Lifetime." Manuscript, Duke University. 
Arthur, W. B. 1981. “The Economics of Risk to Life.” American Economic Review 71, no. 1 (March): $54-64$.

Becker, Gary S., Tomas J. Philipson, and Rodrigo R. Soares. 2005. "The Quantity and Quality of Life and the Evolution of World Inequality." American Economic Review 95, no. 1 (March): 277-291.

Cajner, Tomaz, Leland D Crane, Ryan A Decker, John Grigsby, Adrian Hamins-Puertolas, Erik Hurst, Christopher Kurz, and Ahu Yildirmaz. 2020. "The U.S. Labor Market during the Beginning of the Pandemic Recession." Working Paper, Working Paper Series 27159, National Bureau of Economic Research, May. doi:10.3386/w27159. http://www. nber.org/papers / w27159.

Cutler, David M., and Mark McClellan. 2001. "Is Technological Change in Medicine Worth It?" Health Affairs 20 (5): 11-29.

Ferguson, Neil M., Daniel Laydon, Gemma Nedjati-Gilani, Natsuko Imai, Kylie Ainslie, Marc Baguelin, Sangeeta Bhatia, Adhiratha Boonyasiri, Zulma Cucunubá, Gina Cuomo-Dannenburg, et al. 2020. "Impact of Non-Pharmaceutical interventions (NPIs) to Reduce COVID-19 Mortality and Healthcare Demand." London: Imperial College COVID-19 Response Team, March 16.

Goldstein, Joshua R., and Ronald D. Lee. 2020. "Demographic Perspectives on Mortality of Covid19 and Other Epidemics." Working Paper, Working Paper Series 27043, National Bureau of Economic Research, April. doi:10.3386/w27043. http://www.nber.org/papers / w27043.

Greenstone, Michael, and Vishan Nigam. 2020. "Does Social Distancing Matter?" University of Chicago, Becker Friedman Institute for Economics Working Paper. March.

Gross, Cary P., Utibe R. Essien, Saamir Pasha, Jacob R. Gross, Shi-yi Wang, and Marcella NunezSmith. 2020. "Racial and Ethnic Disparities in Population Level Covid-19 Mortality." medRxiv.

Hall, Robert E., and Charles I. Jones. 2007. "The Value of Life and the Rise in Health Spending." Quarterly Journal of Economics 122, no. 1 (February): 39-72.

Hanlon, P., F. Chadwick, A. Shah, R. Wood, J. Minton, G. McCartney, C. Fischbacher, et al. 2020. "COVID-19 - Exploring the Implications of Long-Term Condition Type and Extent of Multimorbidity on Years of Life Lost: A Modelling Study." Wellcome Open Research 5 (75). doi:10.12688/wellcomeopenres.15849.1.

Jones, Charles I., and Peter J. Klenow. 2016. "Beyond GDP? Welfare across Countries and Time." American Economic Review 106, no. 9 (September): 2426-2457. doi:10.1257/aer. 20110 236. http://www. aeaweb.org/articles?id=10.1257/aer. 20110236.

Kniesner, Thomas J., and W. Kip Viscusi. 2019. "The Value of a Statistical Life." Oxford Research Encyclopedia of Economics and Finance (July). https : / / oxfordre. com / econo mics/view/10 .1093/acrefore/9780190625979.001.0001/acrefore$9780190625979-e-138$.

Murphy, Kevin M., and Robert H. Topel. 2003. Measuring the Gains from Medical Research: An Economic Approach. Chicago: University of Chicago Press.

. 2006. "The Value of Health and Longevity." Journal of Political Economy 114 (5): 871-904.

Nordhaus, William D. 2003. "The Health of Nations: The Contribution of Improved Health to Living Standards." In Murphy and Topel 2003, 9-40.

Schelling, Thomas C. 1968. "The Life You Save May Be Your Own.” In Problems in Public Expenditure Analysis, edited by Jr. Samuel B. Chase, 127-161. Washington, D.C.: Brookings Institution.

Shepard, Donald S., and Richard J. Zeckhauser. 1984. "Survival versus Consumption.” Management Science 30:423-439.

Stock, James H. 2020. "Data Gaps and the Policy Response to the Novel Coronavirus." Working Paper, Working Paper Series 26902, National Bureau of Economic Research, March. doi:10 . 3386/w26902. http://www.nber.org/papers/w26902. 
Thunström, Linda, Stephen C Newbold, David Finnoff, Madison Ashworth, and Jason F Shogren. 2020. "The Benefits and Costs of Using Social Distancing to Flatten the Curve for COVID-19." Journal of Benefit-Cost Analysis.

U.S. Environmental Protection Agency. 2020. "Mortality Risk Valuation.” Technical report. Accessed April 20,2020. https://www.epa.gov/environmental-economics/mortalit y-risk-valuation\#whatvalue.

Usher, Daniel. 1973. "An Imputation to the Measure of Economic Growth for Changes in Life Expectancy.” In The Measurement of Economic and Social Performance, edited by M. Moss, 193-232. New York: National Bureau of Economic Research.

Wilson, Linus. 2020. "SARS-CoV-2, COVID-19, Infection Fatality Rate (IFR) Implied by the Serology, Antibody, Testing in New York City."

Zingales, Luigi. 2020. "Captured Western Governments Are Failing the Coronavirus Test." PROMARKET. https : / / promarket . org/2020/03/13/ captured-westerngovernments-are-failing-the-coronavirus-test/. 